\title{
The first step toward a cure is knowledge of the disease. Old proverb
}

\author{
Fernando Ovalle-Gallardo* \\ Division of Endocrinology, Clinic of Diabetes, Kirklin Clinic, School of Medicine, University of Alabama, Birmingham, Alabama, USA
}

When a patient is diagnosed with diabetes mellitus for the $1^{\text {st }}$ time, the following step should be to immediately establish the most appropriate treatment to achieve control of the disease. Undoubtedly, this raises a series of possibilities that depend on multiple circumstances. I believe that reading the article: "pragmatic Approach to the Treatment of Diabetes Mellitus" can significantly help us select the best possible treatment; the title is very suggestive, and in my opinion, its contents are as well. It meets the expectations that the author surely sets for the article by presenting the information in a clear, simple, and practical manner. In a way, the article is also original, as it focuses on the role of education in the management of diabetes and on insulin as the most important element of treatment. With this approach, it allows the physician to select the best route to control the disease.

As is well-known, the prevalence of diabetes is very high, which requires patients to be treated by general practitioners, family practitioners, or internists. Due to the magnitude of the problem, it would not be possible for everyone to be treated by a diabetes expert. However, it is evident that this article provides a practical guide that is appropriate for every physician to use.

The raising of three basic questions and their respective answers permits a revision, simplistic but adjusted to reality, of the most important aspects of the physiopathology of the disease and a simple approach to its treatment.
This way of approaching the management of diabetes allows us to achieve (for the most part) what is already established in the classical study diabetes control and complications trial ${ }^{1}$ that demonstrated that a tight diabetes control is capable of avoiding or delaying the dreadful chronic complications of the disease.

What does diabetes control consists of?

How do we achieve diabetes control?

How do we evaluate the progression and control of the disease?

These are the three questions that the author considers central. The answers to these three questions are also simple: control consists of "IMITATING NATURE;" we achieve it: "WITH INSULIN;" we evaluate it: "BY SELF-MONITORING" capillary glucose levels at different times during the day.

In this last paragraph, we can practically summarize the entire article; an explanation is given to each of the three points that allow us to understand the physiopathological basis for each one better.

In conclusion, I believe that this article is a very useful tool that will help us establish the initial management of a patient with newly diagnosed diabetes.

\section{Reference}

1. Diabetes Control and Complications Trial Research Group, Nathan DM Genuth S, Lachin J, Cleary P, Crofford O, et al. The effect of intensive treatment of diabetes on the development and progression of long-term complications in insulin-dependent diabetes mellitus. $\mathrm{N}$ Engl $\mathrm{J}$ Med. 1993;329:977-86

\section{Correspondence:}

*Fernando Ovalle-Gallardo

E-mail: jovalle370228@yahoo.com
Available online: $30-09-2019$
Date of reception: 21-05-20

Date of acceptance: 03-06-2019

DOI: 10.24875/RMU.M19000033
Medicina Universitaria. 2019;21(3):89 www.medicinauniversitaria.org
C. This is an open access article under the CC BY-NC-ND license (http://creativecommons.org/licenses/by-nc-nd/4.0/). 